\title{
Comprehensive model for upgrading two-lane road network
}

\author{
Grigorios Papageorgiou • Anastasios Mouratidis • \\ Nikolaos Eliou
}

Received: 18 April 2011 / Accepted: 4 January 2012 / Published online: 22 January 2012

(C) The Author(s) 2012. This article is published with open access at SpringerLink.com

\begin{abstract}
Concept Trough rational approach adapted to the actual condition and needs of national and regional network; a Road Upgrading Management model has been elaborated providing the optimum upgrading strategy in each case. Starting from the simplest to the heaviest and most costly, the model envisages, for each road held for upgrading, the options of 'Maintenance', 'Rehabilitation', 'Reconstruction' and 'New Alignment'.

Methods The choice among these strategies is based on a mathematical algorithm consisting of an effective sequential structure. Facing each concrete case of an aged road, the first step is to proceed to a site survey providing road geometric features, pavement characteristics and traffic volume. The level of service (LOS) derived is compared to the level of service required. While proceeding to the threshold examination of geometric features in a realistic way, the proposed model provides respective appropriate values related to actual needs. Results After an exhaustive consideration of geometric features and indices of environmental, socio-economic adaptation, the upgrading strategies are examined and eventually overruled one by one, finally leading to the optimum alternative.

Conclusions This paper deals with the main issue of quantitative and qualitative criteria definition, in order to proceed to such a full road condition assessment. Road authorities can use this approach as a reliable tool in the frames of an effective road upgrading management.
\end{abstract}

G. Papageorgiou $(\bowtie) \cdot$ N. Eliou

Department of Civil Engineering, University of Thessaly,

Volos 38334, Greece

e-mail: papageor@anhma.gr

A. Mouratidis

Department of Civil Engineering,

Aristotle University of Thessaloniki,

Thessaloniki 54124, Greece
Keywords Road · Optimization · Upgrading ·

Management $\cdot$ Safety

\section{Initial approach}

Nowadays, the main problem to be faced in the frames of a road management policy is the compliance of old roads, constructed in the 50's or 60's, to new construction standards and traffic needs, through a realistic and comprehensive approach. The model proposed in the paper entitled 'A Rational Approach for Optimization of Road Upgrading' [10] is meant for pointing out to road authorities a way to upgrade each part of the old road network without exceeding expenses in a non-effective way, mitigating impacts of implemented solutions. Additionally, this rational method of upgrading can be useful in terms of classifying roads with respect to their performance and to assess improvement priorities, in accordance with an innovative road management policy. From this scope, the model inquires specific and easy applicable ways of implementing technical observations and measurements of geometric and functional road characteristics. Integration of technical, environmental and social issues is the main prism of approaching. Each one of the four upgrading strategies proposed, refers to specific engineering operations while the term attributed to each option is considered to be the best matching. 'Maintenance', 'Rehabilitation', 'Reconstruction' and 'New Alignment' options are namely selected accordingly, in sequence, with respect to the extent of the intervention. The purpose of this paper is to provide specific quantitative and qualitative criteria for the assessment of road elements adequacy, in order to apply this method in detail. 


\section{Existing models}

In most European countries, a great part of the national and the regional network is quite old. Unless properly rehabilitated, these traditional two-lane roads hardly provide the level of service required by current traffic needs. In the frame of upgrading operations, usually dictated by poor pavement condition or low level of service (LOS), the common practice consists of resurfacing the trafficked surface. The basic alignment features remain unchanged. This may result in a good-looking restored structure which, however, presents significant deficiencies with respect to bearing capacity and alignment suitability.

The existing road upgrading models mainly deal with pavement resurfacing. In 1980, the Transportation Research Board (TRB) introduces a 'Decision Methodology for Maintenance and Upgrading' of low-volume roads, estimating maintenance cost and proposes a Generalised Road Roughness Index for Worldwide Use [14]. In the same direction, the Minnesota Department of Transport (Mn/ DOT) uses three indices to report and quantify pavement condition [9]. The main outputs of the Highway Development and Management Manual [18] include prediction of pavement performance and maintenance, road improvement effects, user costs and benefits, estimates of environmental effects, standard economic indicators etc. In 2003, TRB publishes the results of a research entitled 'Geometric Design Consistency on High-Speed Rural Two-Lane Roadways' [16]. The quintessence of this particular research is focused in the definition of term 'design consistency' as follows: 'Design consistency is the conformance of a highway's geometric and operational features with driver expectancy'. The research team developed the basis for an expert system on design consistency to supplement work done by others in the development of FHWA's Interactive Highway Safety Design Model (IHSDM). In order to place the proposed design consistency system into perspective, a brief review of previous research on design consistency is hereafter presented.

An increasing number of jurisdictions classify travel corridor improvements into resurfacing-restoration-rehabilitation (3R) and resurfacing-restoration-rehabilitationreconstruction (4R) projects. In 2001, the Transportation Association of Canada (TAC) Canadian Guide to $3 R / 4 R$ states that a $3 \mathrm{R}$ project will incorporate one or more of resurfacing, restoration, and rehabilitation [13]. A 4R project will also entail reconstruction, which will happen in conjunction with resurfacing, restoration, and rehabilitation.

The Vermont Agency of Transportation [17] has a system that invokes various Level of Improvement (LOI) based, principally on the functional classification of the roads; some classes of roads are not eligible for certain types of improvement under the criteria. Under these criteria, transportation projects involving extensive improvements will only be considered in major corridors. The remaining corridors will be eligible for less extensive improvements based on their Average Annual Daily Traffic (AADT), as well as their importance to state-wide mobility.

For Low Volume Roads (LVR) in Saskatchewan (2007), a similar approach to Vermont has been developed [11]. This approach is based on certain Levels of Improvement (LOI), dependant on the roadway geometrics, the current surface condition rating, as well as the ambient conditions of the travel corridor. It must be recognized that with limited resources, it is not possible to upgrade all LVR in Saskatchewan to the desirable design standards currently outlined in the Design Manual. The objective of various LOI is to maintain safe and efficient operations at the lowest capital costs possible, while ensuring corridor continuity and consistency.

The three LOI in Saskatchewan are Minor Upgrading, Major Upgrading, and Reconstruction. Some key information about the LOI system is:

- The largest percentage of projects is expected to be classified as Minor Upgrading;

- The accident history along the proposed project length is considered to be an indication of the current condition of the roadway and will facilitate the determination of its priority for improvements;

- A Field Review will be completed by an Assessment Team in order to evaluate the current state of the roadway and corridor, so that it can be classified for the various LOI;

- Signing and marking are required for all LOI in the LVR Criteria; and

- Reconstruction is an extreme measure that will seldom be used and only considered on a project by project basis.

Research projects in the past have sought to develop programs that review design consistency either quantitatively $[6,8]$ or qualitatively [2] with varying degrees of success.

As an exception to this rule of purely engineering consideration of a road upgrading project, the Project Development and Design Manual (PDDM) of the Federal Highway Administration [5] proposes an integrated model based on social, economic and environmental (SEE) assessment. However, the manual is general and quite complicated, some of the analysis modules requiring high expertise in the use of the system. Despite the four alternatives proposed for upgrading, the PDDM does not provide specific criteria for the best option.

Deductively, certain models lead to the optimum upgrading alternative by introducing the cost (operations and road users cost) as the only criterion for defining the scope of the engineering project. 


\section{Selected model for road upgrading}

The selected model, in terms of which quantitative and qualitative criteria are presented hereafter, is the aforementioned one proposed by Mouratidis and Papageorgiou [10]. In the frames of this approach, the selected model integrates technical, environmental and social issues. The key elements of selected methodology are the following:

- The optimum upgrading alternative is chosen by specific selection criteria.

- All the important issues, including safety, consistency of alignment, LOS, comfort and environmental adaptation are considered.

- Each old two-lane road is classified into four distinct categories according to its functional/geometric characteristics, LOS provided and environmental adaptation. This classification makes the upgrading plan comprehensive and well determined due to the accurate condition assessment. A specific upgrading plan is foreseen for each road category.

- The first category consists of roads exhibiting a high level of service and adequate geometric features, providing safety and ride comfort. Alignment is suitable; intersections are well designed according to current design standards. Pavement width ensures a satisfactory serviceability. No significant improvement is required. The main problems to face are the appearance of spotted cracks or rutting, the increasing slipperiness and the deficient safety equipment.

- At the second category, the level of service is in the range of stable flow, the geometry is generally suitable; the pavement width is also adequate according to design standards. Adversely, the intersection design proves inadequate with regard to the actual traffic needs and the transition geometry at turns is defective.

- The third category assembles roads with a low level of service. Most geometric elements turn out to be substandard with respect to current traffic situation, thus creating incident risk to road users. Traffic volume seems to have significantly increased through the years and the road use has been intensified. Roadway and lane width do not cover the current traffic needs. The road requires widening and probably realignment integrating current design, safety and traffic standards.

- The fourth and last category includes roads with operating conditions at or near the capacity level where upgrading effectiveness is questionable. An ordinary rehabilitation project can not constitute a sustainable engineering response for an old road in a high sensitivity natural landscape. Additionally, specific inherent constraints for roads in inhabited areas or in the vicinity of archaeological sites may restrict upgrading operations on the existing alignment and prescribe instead a totally new route.

According to the precedent criteria, each road can be classified into one out of the afore-mentioned categories. This classification makes the upgrading plan comprehensive and well determined due to the accurate condition assessment. A specific upgrading plan is foreseen for each road category.

- The different options of road upgrading are classified into four distinct strategies (Fig. 1) presented in sequence with respect to the extent of the intervention and the required operations cost accordingly. The term attributed to each option is considered to be the best matching as follows: 'Maintenance', 'Rehabilitation', 'Reconstruction' and 'New Alignment'.

- In order to achieve an overall evaluation of each upgrading project, the proposed method suggests a road condition inventory and an intended/required performance assessment. According to this approach a fivefold audit of each road segment is held by road authorities as follows:

- Road Condition Inventory

Pavement Condition

Road Safety and Traffic Control Equipment

Road Alignment Characteristics

- Required Performance Assessment

Evaluation of LOS and Safety Criteria

Environmental and Social Aspects

Pavement condition assessment is established through visual inspection of the carriageway, emergency lane and shoulders by competent personnel of road authorities. Video logs and monitoring enhance the relevant information.

Safety and traffic control equipment survey constitutes of visual inspection of guardrails, lighting, markings and signs.

In terms of alignment characteristics, namely the radius of curvature $R_{0}$, the lane width $b_{0}$, the gradient $s$, the cross slope $\mathrm{q}$ and the sight distance $\mathrm{D}$ are recorded through measurements or desk review of the definitive design study.

In terms of performance assessment, the actual traffic volume is calculated by ad loc measurements and the level of service (LOS) is determined by adequate computations of traffic features and comparison with relevant graphical LOS criteria according to the HCM (Highway Capacity Manual) methodology. Evaluation of safety criteria is based on measurements of the operational speed $\mathrm{V}_{85}$ [12]. In principle, the operational speed corresponds to the ordinary road users' driving behavior and prescribes the desired geometric features ensuring traffic safety. The difference between operational and design speed considered in parallel with the 
Fig. 1 Road upgrading structure (Source: [10])

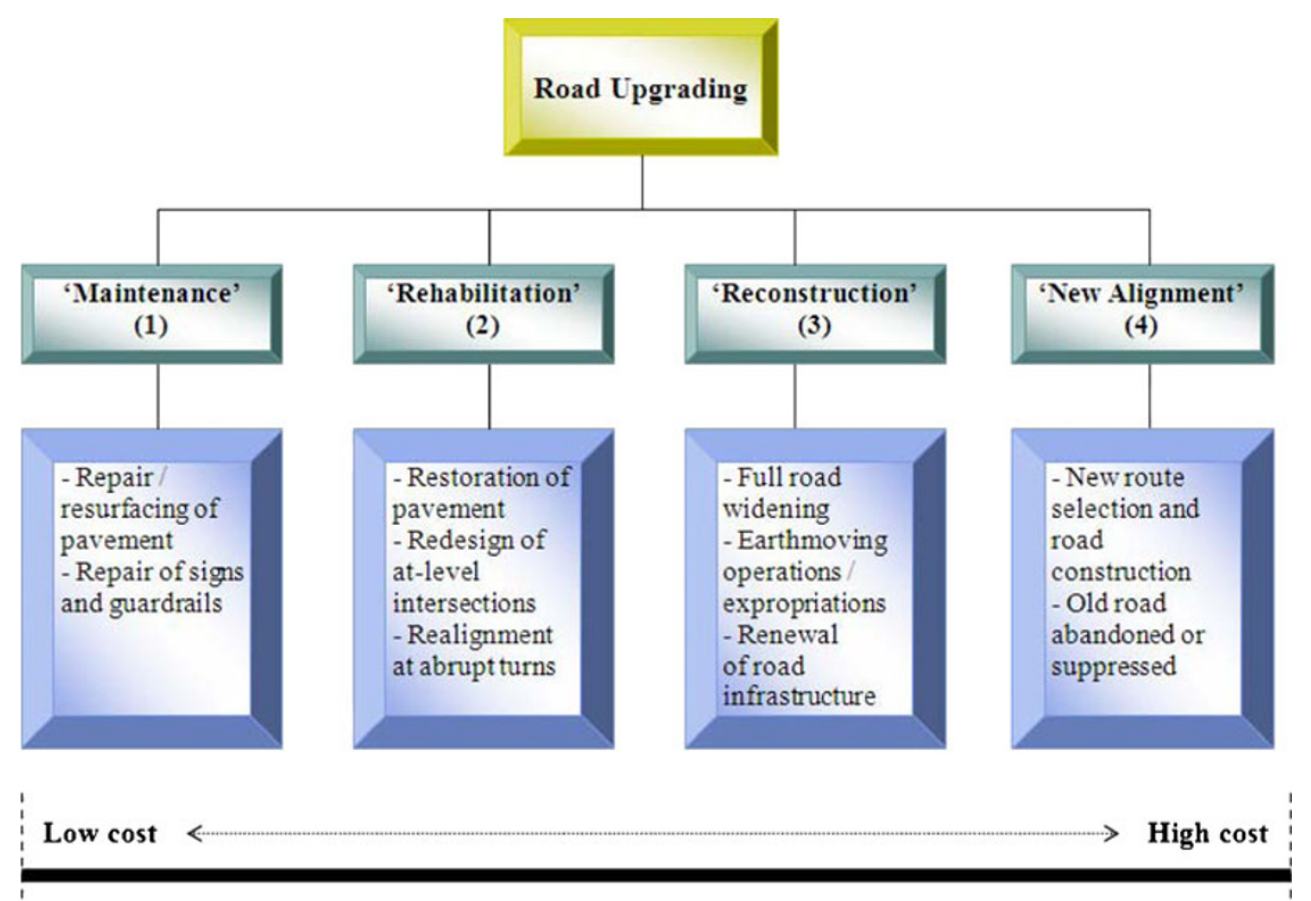

divergence of the operational speed between two sequential road design elements ('straightway-curve' or 'curve-curve') derives to the characterization of road design quality in terms of safety and comfort.

As far as the environmental and the social aspects of the intended rehabilitation are concerned, a complete procedure for selection of the best option must include an appropriate final audit. Formerly constructed roads may have not produced negative impact to the environment for many decades, as long as the volume of traffic remained limited and vehicle speed low. The increase in traffic volume may induce unexpected degradation to the environment.

Additionally, inherent constraints, such as the proximity to historical/archaeological sites or environmentally protected areas close to the road are also considered to be decisive for the selection of the optimum upgrading option. Finally, the existing road alignment through inhabited areas may be reconsidered because of a high accident rate.

Implementing road condition characteristics and required performance data to the constitutive algorithm as in Table 1, the preferable upgrading option is derived following a precise and rational methodology.

\section{Selection criteria for road categorization}

The proposed model adopts a segment methodology which applies to road segments of at least $3 \mathrm{~km} \mathrm{[15]} \mathrm{or} \mathrm{to} \mathrm{road}$ segments between two at-grade intersections, so as to face variability of geometric and performance features among road segments. The quantitative and qualitative selection criteria for the best upgrading option are presented hereafter.

\subsection{Road condition evaluation}

Road condition evaluation deals with pavement surface, safety and traffic control equipment and alignment features as follows.

\subsubsection{Pavement condition assessment}

Pavement distress types such as rutting, cracks, potholes and folding are recorded through visual inspection of the carriageway, emergency lane and shoulders by competent personnel of road authorities. Video logs and monitoring enhance the relevant observations.

\subsubsection{Safety and traffic control equipment survey}

This survey constitutes of visual inspection of guardrails, lighting, markings and signs. The actual condition of examined elements is evaluated as worn out or obsolete in case the equipment is damaged or has to be replaced in order to meet current needs/standards accordingly.

\subsubsection{Alignment characteristics evaluation}

While proceeding to the threshold examination of geometric features in a realistic way, the proposed model provides an audit of the main geometric characteristics. Accordingly, a divergence limit or a threshold value for each geometric characteristic, compared to standard values, is set forth. 


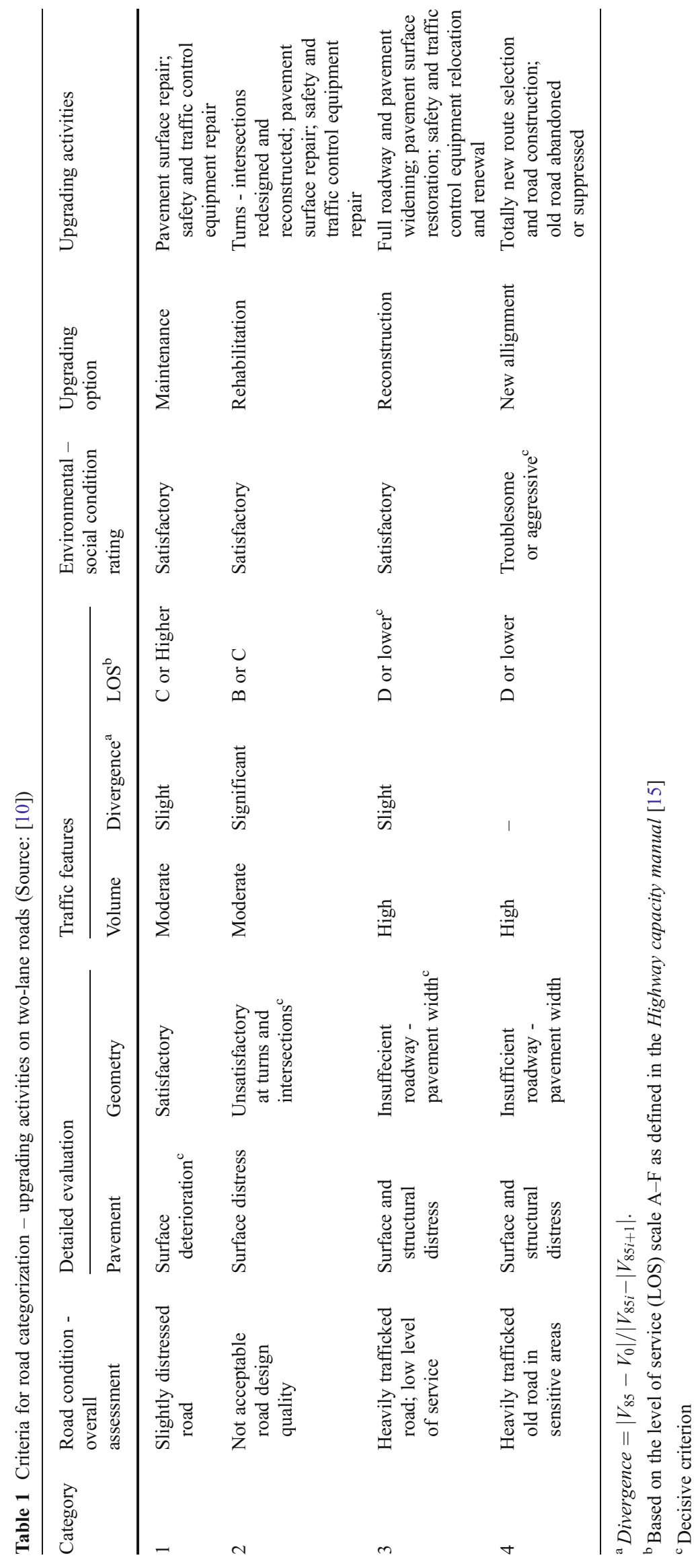


Table 2 Allowable values for road geometric features

\begin{tabular}{|c|c|c|c|c|c|c|c|c|}
\hline \multirow[t]{4}{*}{ Network } & \multirow[t]{4}{*}{$\mathrm{V}_{0}(\mathrm{~km} / \mathrm{h})$} & \multirow[t]{4}{*}{ lane width (m) } & \multicolumn{6}{|c|}{$\mathrm{R}_{\min }, \mathrm{q}_{\max }, \mathrm{s}_{\max }$} \\
\hline & & & \multicolumn{2}{|c|}{ Flat ground } & \multicolumn{2}{|c|}{ Hilly ground } & \multicolumn{2}{|c|}{ Mountainous ground } \\
\hline & & & \multicolumn{2}{|l|}{$\mathrm{q}_{\max }=8 \%$} & \multicolumn{2}{|l|}{$\mathrm{q}_{\max }=7 \%$} & \multicolumn{2}{|c|}{$\mathrm{q}_{\max }=7 \%$} \\
\hline & & & $\mathrm{R}_{\min }(\mathrm{m})$ & $\mathrm{s}_{\max }(\%)$ & $\mathrm{R}_{\min }(\mathrm{m})$ & $\mathrm{s}_{\max }(\%)$ & $\mathrm{R}_{\min }(\mathrm{m})$ & $\mathrm{s}_{\max }(\%)$ \\
\hline Regional & 60 & 3.25 & 125 & 6 & 140 & 7 & 140 & 9 \\
\hline Regional/National & 80 & 3.50 & 250 & 4 & 280 & 5 & 280 & 7 \\
\hline National & 100 & 3.75 & 420 & 3 & 480 & 4 & 480 & 6 \\
\hline
\end{tabular}

where: $\mathrm{V}_{0}=$ design speed, $\mathrm{q}=$ pavement crossfall, $\mathrm{s}=$ profile gradient

Fig. 2 Adequate stopping sight distance for wet pavements (Source: [12])

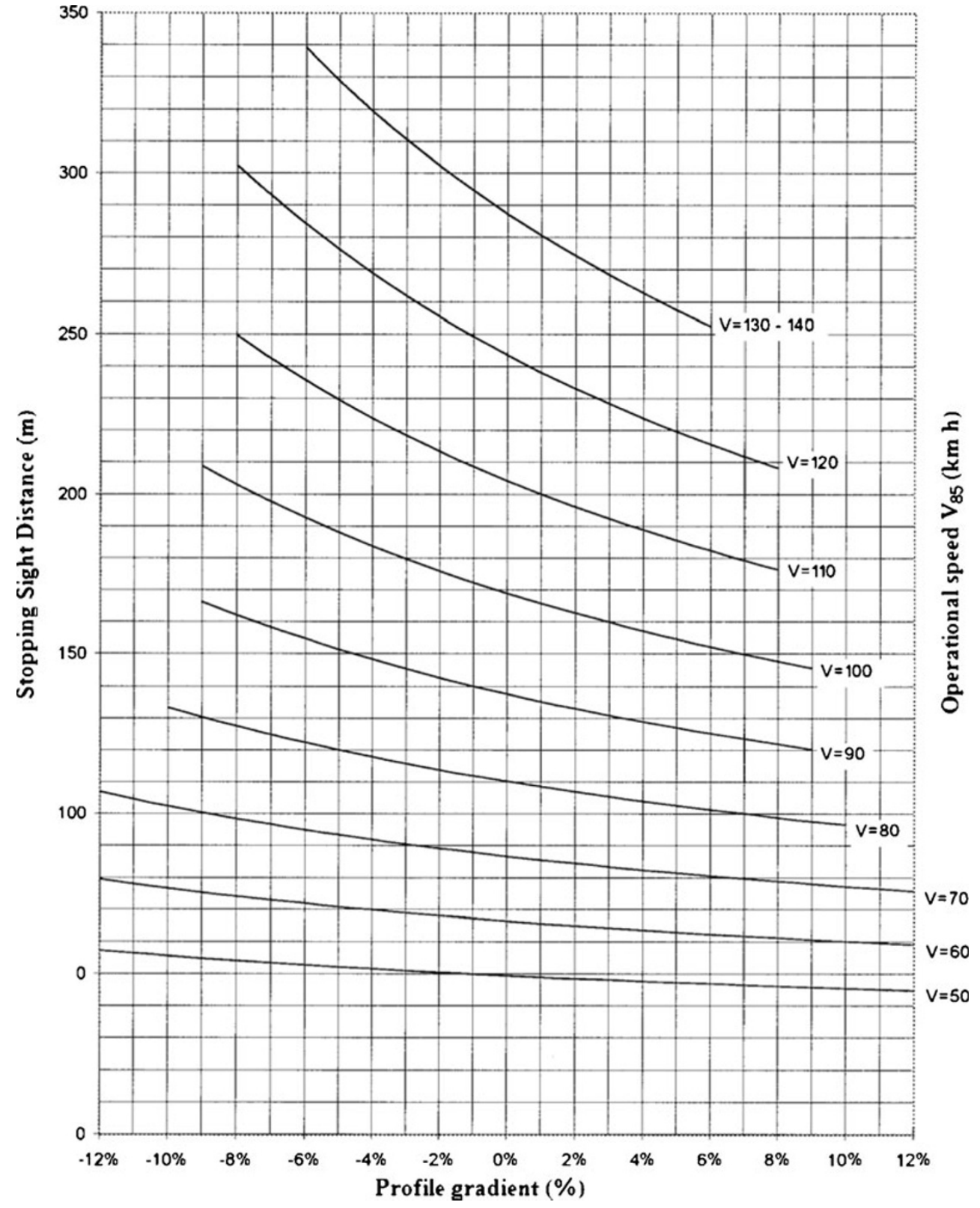


Table 3 Intersection sight distance (Source: [7])

\begin{tabular}{lll}
\hline $\begin{array}{l}\text { Design } \\
\text { speed } \\
(\mathrm{km} / \mathrm{h})\end{array}$ & $\begin{array}{l}\text { Intersection sight } \\
\text { distance left-turn } \\
\text { movements }(\mathrm{m})\end{array}$ & $\begin{array}{l}\text { Intersection sight } \\
\text { distance straight-across } \\
\text { movements }(\mathrm{m})\end{array}$ \\
\hline 20 & 45 & 40 \\
30 & 65 & 55 \\
40 & 85 & 75 \\
50 & 105 & 95 \\
60 & 130 & 110 \\
70 & 150 & 130 \\
80 & 170 & 145 \\
90 & 190 & 165 \\
100 & 210 & 185 \\
110 & 230 & 200 \\
120 & 255 & 220 \\
130 & 275 & 235 \\
\hline
\end{tabular}

Divergence range takes into consideration the road functional classification [12], meaning that overcoming this divergence points out to change of road functional category. In terms of geometric characteristics evaluation, Table 2 indicates threshold values of geometric features for national and regional network.

Stopping sight distance (SSD) is evaluated through the whole roadway following the American Association of State Highway and Transportation Officials [1] design policy and decision sight distance (DSD) is evaluated on at-grade intersections according to the guidelines presented in Chapter 6A-4 of the Design Manual of Iowa Department of Transportation [7]. The required SSD values are extracted from the graph in Fig. 2 with respect to $V_{85}$ and profile gradient. The required DSD is taken from Table 3 adjusted for skew angle according to Table 4.

Cross slope and superelevation are recorded through measurements or desk review of the final road design if available and compared to standard minimum and maximum values accordingly [12].

Radii of curvature are compared to standard minimum values given by the guidelines in terms of design speed. If design speed is unknown, operational speed $V_{85}$ may be used as design speed for minimum radius of curvature values.

Lane width is compared to standard values in terms of design speed. The rule for assessing the consistency of lane

Table 4 Adjustment factor for skew angle (Source: [7]). Factor values should be aligned vertically with Grade values

\begin{tabular}{llllll}
\hline Grade & 90 & 80 & 70 & 60 & 45 \\
Factor & 1.00 & 1.01 & 1.03 & 1.06 & 1.17 \\
\hline
\end{tabular}

* Factors may be interpolated directly. Significant (especially between $60-45$ values) regarding that Grade values vary

Table 5 Bridge widths (Source: [4])

\begin{tabular}{ll}
\hline Design Year Volume (ADT) & Usable Bridge Width (m) \\
\hline $0-750$ & Width of approach lanes \\
$751-2,000$ & Width of approach lanes plus $0.6 \mathrm{~m}$ \\
$2,001-4,000$ & Width of approach lanes plus $1.2 \mathrm{~m}$ \\
Over 4,000 & Width of approach lanes plus $1.8 \mathrm{~m}$ \\
\hline
\end{tabular}

width relies on the fact that narrow lanes are associated with increased run-off-the-road, head-on, opposite-direction sideswipe, and same-direction sideswipe accidents. According to the National Cooperative Highway Research Program Report 502, entitled 'Geometric Design Consistency on High-Speed Rural Two-Lane Roadways', reductions in lane width associated with a greater than $5 \%$ increase in accident risk are flagged as inconsistencies. This percentage of increased accident rate corresponds to a reduced per 0.30 meters lane width when the average daily traffic (ADT) is over 2,000 vehicles. Considering a rather more conservative evaluation of design consistency, the accepted divergence between actual lane width and standard values is set to 0.25 meters. Reduction of lane width equal to 0.25 meters corresponds in most cases to change of road functional category according to the Guidelines for Designing Road Works [12].

Bridge widths are evaluated on a case-by-case basis of the design year volume (ADT) as suggested in Table 5. If lane widening is planned as part of the upgrading option selected, the usable bridge width should be compared with the planned width of the approach lanes after they are widened.

Finally, the gradient $s$ is recorded through adequate measurements and compared with maximum standard values required by the guidelines [12].

The acceptable divergence for each one of the above geometric characteristics is shown in Table 6.

\subsection{Required performance assessment}

The required performance assessment is consisted of LOS calculation, safety criteria audit and environmental/social adaptation of road alignment as follows.

Table 6 Criteria of acceptable divergence for geometric characteristics Geometric characteristic

Threshold values/ acceptable divergence

Stopping/Decision Sight

Distance (min values)

Cross slope/superelevation

( $\mathrm{min} / \mathrm{max}$ values)

Radius of curvature (min values)

Lane width (min values)

Gradient (max values)

$$
\begin{aligned}
& \mathrm{D}_{\mathrm{i}}<\mathrm{D}_{\text {min }} \\
& 2.5 \%<\mathrm{q}<\mathrm{q}_{\max } \\
& \mathrm{R}_{\mathrm{i}}<\mathrm{R}_{\text {min }} \\
& \left|b_{i}-b_{r e q}\right| \leq 0.25 m \\
& \mathrm{~s}_{\mathrm{i}}-\mathrm{s}_{\text {max }}<1 \%
\end{aligned}
$$




\subsubsection{Evaluation of LOS}

Facing a concrete case of an aged road, the next step is to proceed to a site survey providing the road traffic volume $Q_{0}$ and the LOS. As design year for the upgrading operations is set the 20th year after the opening to traffic of the upgraded road considering this time interval a sufficient life-cycle of an upgraded typical two-lane roadway.

Design year LOS is determined by adequate computations of traffic features and comparison with relevant graphical LOS criteria according to the HCM methodology [15].

\subsubsection{Safety criteria}

Whether design speed $V_{0}$ of old existing roads is unknown, operational speed $V_{85}$ is considered as the required design speed. In principle, the operational speed corresponds to the ordinary road users driving behavior and prescribes the desired geometric features ensuring traffic safety. The difference between operational and design speed considered in parallel with the divergence of operational speed between two sequential road design elements ('straightway-curve' or 'curvecurve') derives to characterization of road design quality in terms of safety and comfort. Thus, an alignment that influences proportionally the road behavior of drivers is shaped and two fundamental objectives of upgrading are achieved:

1. Design speed remains constant in a road segment of sufficient length or in road segments that constitute characteristic units and have similar functional characteristics.

2. Over-estimation or under-estimation of design elements are avoided in the road segment.

The studies for optimization and improvement on existing roads can in certain cases become admissible at economy whether they are evaluated with regard to design quality as mediocre ('acceptable', Table 7).

The criteria presented above are fulfilled accordingly when:

1. $V_{85}-V_{0} \leq 20 \mathrm{~km} / \mathrm{h}[12]$ and

2. $V_{85 i}-V_{85(i+1)} \leq 15 \mathrm{~km} / \mathrm{h}[12]$

In case the divergence between $V_{85}$ and $V_{0}$ is less than $10 \mathrm{~km} / \mathrm{h}$, no further improvement is needed in geometric features. 'Maintenance' consists of pavement resurfacing
Table 8 Road quality according to LOS

\begin{tabular}{llll}
\hline Network & \multicolumn{2}{l}{ Appropriateness with regard to LOS } \\
\cline { 2 - 4 } & Good & Acceptable & Not Acceptable \\
\hline $\begin{array}{c}\text { Regional/ } \\
\text { National }\end{array}$ & LOS = A or B & LOS $=$ C (D*) & LOS = D or lower \\
\hline
\end{tabular}

* only in case of budget restraints

and replacement of worn out safety and traffic control equipment. Whether this divergence exceeds $10 \mathrm{~km} / \mathrm{h}$ staying less than $20 \mathrm{~km} / \mathrm{h}$, the crossfalls need recalculation based on $V_{85}$, in order to ensure safe grip features. Whenever this is not possible, the placement of suitable warning signs is recommended instead.

\subsubsection{Environmental and social aspects}

Roads constructed in past decades may induce severe impact to the environment. The degree of this impact depends on inherent constraints such as the proximity to historical/archaeological sites or environmentally protected areas close to the roadway and is hardly quantified. Nevertheless, there is no doubt that the adaptation of road geometric and traffic characteristics in the environment is a determinative factor to be considered in order to start upgrading activities. The degree of environmental adaptation is hardly quantified, so a qualitative rating of the existing alignment is set forth. The environmental impact is troublesome or aggressive in case historical or archaeological monuments are close to the road. An alignment through environmentally protected areas seems to be a severe constraint for upgrading operations on the existing alignment.

In terms of social impact, the existing road alignment through inhabited areas is evaluated in the frames of accident rate.

\section{Methodology for selection of alternative strategies}

In order to conclude to the best option of upgrading, each road segment is examined through the above selection criteria. Depending on the results of the above audit, the model leads to road categorization and accordingly to the optimum upgrading strategy.

Table 7 Criteria of road design quality

\begin{tabular}{llll}
\hline Safety Criterion & Road Design Quality & & Not Acceptable \\
\cline { 2 - 4 } & Good & Acceptable & $20 \mathrm{~km} / \mathrm{h}<\left|\mathrm{V}_{85}-\mathrm{V}_{0}\right|$ \\
I & $\left|V_{85}-V_{0}\right|<10 \mathrm{Km} / \mathrm{h}$ & $10 \mathrm{~km} / \mathrm{h} \leq\left|V_{85}-V_{0}\right| \leq 20 \mathrm{~km} / \mathrm{h}$ & $15 \mathrm{~km} / \mathrm{h}<\left|V_{85 i}-V_{85(i+1)}\right|$ \\
II & $\left|V_{85 i}-V_{85(i+1)}\right|<10 \mathrm{~km} / \mathrm{h}$ & $10 \mathrm{~km} / \mathrm{h} \leq\left|V_{85 i}-V_{85(i+1)}\right| \leq 15 \mathrm{~km} / \mathrm{h}$ & 1 \\
\hline
\end{tabular}

where: $V_{85}=$ operational speed, $V_{0}=$ design speed and $i=$ the number of curve 
Table 9 Corrective factor for environmental adaptation

Environmental/social constraints

Historical/archaeological sites close to the road

Road alignment through or close to environmentally protected areas

Alignment through inhabited areas - Increase of accident rate

Danger of pollution by heavily trafficked roads

\subsection{Conformity control for 'maintenance' option}

Pavement surface is deteriorated, cracks, potholes, rutting and other distress types are observed. Safety and traffic control equipment is worn out. Geometric characteristics proved to be satisfactory. Design year LOS is calculated to be ' $C$ ' or higher and the safety criteria are fulfilled. Finally, environmental and social condition rating is estimated to be satisfactory. If this is the case, the model demonstrates a slightly distressed road and the 'Maintenance' option is derived.

Upgrading activities consist of pavement surface repair according to guidelines and repair of deteriorated equipment elements.

\subsection{Geometric and operational control for 'rehabilitation'} option

Providing a ' $\mathrm{B}$ ' or ' $\mathrm{C}$ ' LOS and a satisfactory environmental/social condition rating, the decisive criterion for the selection of the 'Rehabilitation' option as the best upgrading strategy is the adequacy of geometry at turns and intersections. In case at least one of the selection criteria for the evaluation of alignment characteristics (Table 2) is not satisfied, the 'Rehabilitation' is selected as best upgrading option.

Even if geometric characteristics are proved to be adequate, the safety criteria presented above (Table 7) give a more sophisticated view of the roadway quality in terms of safety and comfort. In case one of the safety criteria is not satisfied, 'Rehabilitation' operations are selected as appropriate.

Operations consist of redesign and reconstruction of curves and at-grade intersections, local or extended pavement surface repair of pavement and replacement of damaged or inappropriate safety and traffic control equipment.

The applicable radius of curvature $R_{r e q}$ and the recommended lane width $l_{\text {req }}$ are given in Table 2 . Thus, for a twocurve road segment $R_{i}\left(R_{1}, R_{2}\right)$ is increased to $R_{\text {req }}\left(R_{1}^{\prime}, R_{2}^{\prime}\right)$ in order to meet the updated design standards $\left(R_{1}^{\prime}, R_{2}^{\prime}=\right.$ minimum design value of radius of curvature according to current design standards; $\mathrm{R}_{1}, \mathrm{R}_{2}=$ existing values of radius of curvature).

\subsection{Adequacy of roadway and LOS for 'reconstruction' option}

'Reconstruction' consists of widening, redesign of radius of curvature and extension of infrastructure. Once the applicable radii of curvature $\left(R_{1}^{\prime}, R_{2}^{\prime}\right)$ are determined for each turn, it is necessary to proceed to full design of the road segment, that is, alignment characteristics, lane width, gradient and crossfall. The re-design of the road segment determines the earthwork volume, the structures to be extended and the eventual expropriations.

In terms of a cost effective management policy, the percentage of maximum allowed traffic volume must reflect to sufficient road exploitation. Thus, the minimum exploitation rate for existing two-lane roads is defined to $40 \%$. Consequently, $\operatorname{LOS}$ ' $\mathrm{C}$ ' is defined as best for use. On the contrary, the minimum acceptable LOS is ' $D$ ' (Table 8).

As regards the design time period for traffic volume, it refers to 20-25 years at least, meaning estimated traffic volumes attributed to $\operatorname{LOS}$ ' $C$ ' or ' $D$ ' in case of budget restraints.

Table 10 Selection of optimum upgrading strategy

\begin{tabular}{|c|c|c|c|c|c|c|}
\hline Selection criteria & $\begin{array}{l}\text { Pavement } \\
\text { deterioration }\end{array}$ & $\begin{array}{l}\text { Worn or obsolete } \\
\text { safety \& traffic } \\
\text { control equipment }\end{array}$ & $\begin{array}{l}\text { Inadequate } \\
\text { geometry }\end{array}$ & $\begin{array}{l}\text { Significant divergence } \\
\left|V_{85}-V_{0}\right|,\left|V_{85 i}-V_{85 i+1}\right|\end{array}$ & $\begin{array}{l}\text { Insufficient roadway/ } \\
\text { pavement width }\end{array}$ & $\begin{array}{l}\text { Low } \\
\text { LOS }\end{array}$ \\
\hline Pavement deterioration & 1 & & & & & \\
\hline $\begin{array}{l}\text { Worn or obsolete safety \& } \\
\text { traffic control equipment }\end{array}$ & 1 & 1 & & & & \\
\hline Inadequate geometry & 2 & 2 & 2 & & & \\
\hline $\begin{array}{l}\text { Significant divergence } \\
\left|\mathrm{V}_{85}-\mathrm{V}_{0}\right|,\left|\mathrm{V}_{85 \mathrm{i}}-\mathrm{V}_{85 \mathrm{i}+1}\right|\end{array}$ & 2 & 2 & 2 & 2 & & \\
\hline Insufficient roadway/pavement width & 3 & 3 & 3 & 3 & 3 & \\
\hline Low LOS & 3 & 3 & 3 & 3 & 3 & 3 \\
\hline $\begin{array}{l}\text { Troublesome or aggressive } \\
\text { environmental adaptation }\end{array}$ & - & - & - & - & 4 & 4 \\
\hline
\end{tabular}


Design year LOS is defined and calculated by adequate computations of traffic features and comparison with relevant graphical LOS criteria according to the HCM methodology (HCM, 2000). The traffic features forecast is calculated by equations relating current traffic feature value and its increase/ decrease rate accordingly with the design year value of traffic feature.

Whether predicted design year LOS (e.g. LOS after 20 years), according to estimated traffic volume, is not acceptable with respect to Table 8 , the model prohibits the 'Rehabilitation' alternative directly deriving to the 3rd strategy, so called 'Reconstruction' as best upgrading option.

In addition, it is considered that adaptation of road in the environment is comprehended as taking of all those suitable metres, so as either the new or the improved existing road wounds as less as possible the natural landscape.

\subsection{Environmental impact assessment of 3rd and 4th option}

After complete evaluation of geometric and operational characteristics of the road and in case first and second choice of upgrading are excluded according to the above methodology, the next and final step stands for investigating the environmental impact of the third option to the local environment. The main effects are presented in Table 9.

Specialized staff of the road agency should consider the limitations of Table 9. In case that one of them exists, an environmental assessment study (EAS) should be prepared. This EAS examines two alternative options namely 'Reconstruction' and 'New Alignment'.

The EAS examines the economic, environmental and social impact and will be processed based on the methodology explained in the CD XI European Directive [3].

\section{Summary—conclusions}

In sum, to implement the proposed model is necessary, in principle, to assess distress of road surface, geometric and functional characteristics, to investigate the safety criteria proposed. If this assessment does not result in one of the first two upgrading options ('Maintenance' and 'Rehabilitation' accordingly), then the main environmental impacts of the third choice ('Reconstruction') are discussed. If one of the effects presented in Table 9 is estimated to show up by 'Reconstruction' implementation, then, at the final stage, an EAS considering the two alternatives of 'Reconstruction' and 'New Alignment' takes place. The outcome of EAS indicates the best option to upgrade the road. Depending on the results of each audit, the best option is selected based on Table 10.

The model presented above, deals with the establishment of an easily applicable model for existing road upgrading, into a holistic approach, taking into account safety, comfort, socioeconomic and environmental parameters raised either by the current road condition or by the upgrading operations. Into that prism, the road network has to be classified in terms of the four categories proposed. The proposed model provides quantitative and qualitative criteria to lead road authorities to the best upgrading alternative, without exceeding expenses and, at the same time, adapting to the environmental status. The aforementioned criteria are used to identify the exact road deficiencies so as to avoid pointless upgrading operations but to face only the real defects.

Open Access This article is distributed under the terms of the Creative Commons Attribution License which permits any use, distribution and reproduction in any medium, provided the original author(s) and source are credited.

\section{References}

1. AASHTO (2004) A policy of geometric design of highways and streets. American Association of State Highway and Transportation Officials (AASHTO), Washington, DC

2. Alexander GJ, Lunenfeld H (1986) Driver expectancy in highway design and traffic operations. Federal Highway Administration (FHWA), US Department of Transportation, Washington

3. European Commission (1995) European Directive CD XI. Environmental Impact Assessment: Methodology and Research

4. FHWA (1988) October 17. Technical Advisory T 5040. 28, Developing Geometric Design Criteria and Processes for Nonfreeway RRR Projects. Federal Highway Administration (FHWA), U.S. Department of Transportation, Washington, DC

5. FHWA (1996) Project development and design manual (PDDM). Federal Highway Administration (FHWA), U.S. Department of Transportation, Washington, DC

6. Fitzpatrick K, Wooldridge MD, Tsimhoni OJ, Collins M, Green P, Bauer KM, Parma KD, Koppa RD, Harwood W, Anderson I, Krammes RA, Poggioli B (2000) Alternative design consistency rating methods for two-lane rural highways. Report FHWA-RD99-172, Federal Highway Administration (FHWA), US Department of Transportation, Washington, DC

7. IDT (2004) Design Manual. Chapter 6A-4. Iowa Department of Transportation (IDT). Des Moines

8. Messer CJ (1980) Methodology for evaluating geometric design consistency. In Facility design and operational effects. Transportation Research Record 757, Transportation Research Board, National Research Council, Washington, D.C., pp. 7-14

9. Mn/DOT (2007) Road design manual (RDM). Minnesota Department of Transportation (Mn/DOT), Minneapolis, Mn

10. Mouratidis A, Papageorgiou G (2010) A Rational Approach for Optimization of Road Upgrading. Canadian Journal of Civil Engineering, ISSN (print): 0315-1468, ISSN (electronic): 1208-6029, NRC Research Press (Canadian Science Publishing), Ottawa, Ont., Volume: 37, Number 11, pp. 1462-1470

11. Retzlaff H, Sukhy K, Podborochynski D, Krawec J (2007) Guidelines for upgrading low volume roads in Saskatchewan. In Proceedings of the 2007 Annual Conference of the Transportation Association of Canada, Saskatoon, Sask., 14-17 October 2007. CD-ROM. Transportation Association of Canada, Ottawa, Ont 
12. Special Committee for Processing Issues of European Network (2001) Instructions of road operation studies for Greece. Special Committee for Processing Issues of European Network. Greek Ministry of Environment, Planning and Public Works, General Secretariat of Public Works, Athens, Greece

13. TAC (2001) Canadian Guide to 3R/4R. Transportation Association of Canada (TAC), Ottawa, Ont.

14. TRB (1980) Decision methodology for maintenance and upgrading. Transportation Research Board (TRB), National Research Council, Washington, DC
15. TRB (2000) Highway capacity manual (HCM). Transportation Research Board (TRB), National Research Council, Washington, DC

16. TRB (2003) Geometric design consistency on high-speed rural two-lane roadways. NCHRP 502, Transportation Research Board (TRB), National Research Council, Washington, DC

17. Vermont Agency of Transportation (1997) Vermont State design standards. Vermont Agency of Transportation, Montpelier, Vt.

18. World Road Association (2005) The highway development and management system (HDM-4). Version 2.0. World Road Association (PIARC), La Defense, France 